\title{
Advances in Dissociation Research and Practice in Israel
}

\author{
Eli Somer \\ $\equiv$
}

SUMMARY. This essay covers the field of dissociation in Israel as reflected in publications by Israeli contributors and their collaborators both in the Hebrew language and in the international literature. With 140 references, this article covers the 24-year history of the field in this Middle Eastern country presenting documentations on dissociation in indigenous Middle Eastern culture, dissociation and the trauma of the Holocaust, a discussion of the "memory wars" in Israel, a portrayal of Israeli training programs in the field, an account of writing and publicity on dissociative disorders, a report on the process of acceptance of the concept in Israel and the development of advocacy in the field, as well as information on controlled Israeli research and clinical publications on dissociation. This literature review seems to indicate that dissociation is a useful paradigm that has aided Israeli scholars in the understanding of disavowed experiences in a variety of contexts. [Article copies available for a fee from The Haworth Document Delivery Service: 1-800-HAWORTH. E-mail address: <docdelivery@haworthpress.com> Website: <http://www.HaworthPress.com> (C) 2005 by The Haworth Press, Inc. All rights reserved.]

Eli Somer, PhD, is affiliated with the University of Haifa, Israel.

Address correspondence to: Eli Somer, $\mathrm{PhD}$, Israel Institute for Treatment and Study of Stress, 5 David Pinski Street, Haifa 34351, Israel.

The author wishes to acknowledge Erez Zwerling for his invaluable assistance with the media and literature search.

[Haworth co-indexing entry note]: "Advances in Dissociation Research and Practice in Israel.” Somer, Eli. Co-published simultaneously in Journal of Trauma Practice (The Haworth Maltreatment \& Trauma Press, an imprint of The Haworth Press, Inc.) Vol. 4, No. 1/2, 2005, pp. 157-178; and: Trauma and Dissociation in a Cross-Cultural Perspective: Not Just a North American Phenomenon (ed: George F. Rhoades, Jr., and Vedat Sar) The Haworth Maltreatment \& Trauma Press, an imprint of The Haworth Press, Inc., 2005, pp. 157-178. Single or multiple copies of this article are available for a fee from The Haworth Document Delivery Service [1-800-HAWORTH, 9:00 a.m. - 5:00 p.m. (EST). E-mail address: docdelivery@ haworthpress.com].

Available online at http://jtp.haworthpress.com (C) 2005 by The Haworth Press, Inc. All rights reserved. doi:10.1300/J189v04n01_11 
KEYWORDS. Dissociation, Israel, trauma

This essay presents a comprehensive picture of the dissociation field in Israel by describing traditional, popular, clinical and scientific aspects of dissociation in the country. I will present a review of the collective efforts of local academics and clinicians and their international colleagues to study dissociation and its specific manifestations in this heterogeneous culture. Aspects of dissociation that are distinctive of Israeli culture, such as dissociation perspectives of Middle Eastern and Jewish culture, will be described in more detail than more universal topics concerning measurement of dissociation, correlative dissociation research, or clinical case studies.

Dissociation and indigenous Middle Eastern culture. In Jewish families of ancient times and in traditional contemporary Middle Eastern societies, familial needs and social convention have taken precedence over the needs of the individual. Self-esteem, dignity and social identity have been developed by the self-esteem, dignity and social identity of the family. Of the five basic human needs identified by Maslow (1970)(1) physiological/biological needs; (2) the need for safety; (3) the need to belong and feel loved; (4) the need for personal self-esteem; and (5) the need to self-actualize-the first four have been provided by the traditional Middle Eastern family. However, this support is contingent upon individual compliance with the norms, directives and values of the family. This requires that the right to self-actualization be forfeited and that expression of sexual and aggressive feelings be severely curtailed. For example, Mid-Eastern tradition dictates that the individual expresses only love and positive regard for his or her parents. Expressions of frustration, anger or hatred are forbidden, even if the children are neglected or maltreated (Somer, 1977). These social values place certain individual needs (e.g., sexual needs or the need to vent anger) in conflict with the needs and will of the family. As such, the individual in the traditional Mid-Eastern society is forced to choose between one of two options. Making the conformist choice means that the individual has chosen to comply with the will of the family and to place the needs of the family above those of the individual. The individual can than expect to enjoy familial support and to have his or her needs met by the family. In return, one relinquishes needs pertaining to actualization of the self. Aggressive feelings towards members of the immediate and extended family are functionally repressed. The conformist choice actually 
condones intrapsychic dissociation and repression as a means of circumventing conflict between the person and the society at large.

In contrast, the traditional Mid-Eastern individual who makes the "self" choice has decided to individuate from the tribe/family by expressing disagreement with family decisions or norms and/or by choosing to determine one's own life style (e.g., move out from the family compound to live on one's own). These actions will be viewed by the family as unacceptable, resulting in temporary sanctions and eventually the withdrawal of familial support. Although this choice typically leads to decreased intrapsychic repression and dissociation, there is a corresponding increase in conflicts between the person and the society at large. Because traditional Mid-Eastern societies are so characteristically familial, self-assertion by oppressed women is typically met by rejection, sanctions, and inevitably by punishment and ostracizing (if not murder) when sexual issues are involved (Al-Krenawi, 2000; Al-Krenawi, Maoz, \& Shiber, 1995).

These two choices determine whether the individual will face either internal or external conflict. Opposing the family is very difficult because the individual has internalized traditional values as the result of lifelong conditioning. The intrapsychic process of repression and dissociation is further facilitated by two socially sanctioned coping strategies, which are particularly evident among the Druze, Christian and Muslim Arabs of the region and by Jews of Arab descent:

1. Mosaira-the practice of hiding one's true feelings and opinions and behaving only in ways that will please others. This strategy helps to ensure that socially appropriate behavior will be maintained and that rejection and punishment will be avoided.

2. Istigaba-the custom of criticizing others only in their absence, as well as the practice of performing forbidden acts "far from the eyes of society." This enables the individual to vent anger and gratify forbidden sexual drives and to disavow them when under the scrutiny of controlling others (Dwairy, 1993; Dwairy \& Van Sickle, 1996).

Two main factors may affect the severity of the individual-family conflict: the level of acculturation and gender. In traditional Mid-Eastern societies, where women face severe oppression and have no control over significant choices, sanctions against disobedient women often extend to termination of familial support and include home imprisonment, physical beating, clitoral circumcision, and even threats to their lives if 
the "honor of the family" is construed to be threatened. In these societies, complete adherence to existing social expectations is the only choice for females, while Istigaba is not available for venting. The traditional Mid-Eastern woman is forced to regulate the self in order to survive. Under these conditions, the expression of distress is almost always dissociated and somatized (Somer, 1993), particularly if the distress originates in interpersonal conflict. Traditions in these societies allow for dissociated and somatized distress to be expressed in ways that reinforce the supremacy of male-dominated society and validate religion, namely, hysterical conversive, somatoform and possession phenomena (Bilu \& Beit Hallahmi, 1989).

Through these phenomena, forbidden behaviors and expressions of affect are then construed as "non-me" experiences that are outside the woman's realm of control. These loci of control are regarded as Dybbuks (Somer, 1997a, 2004), Jinns, spirits or the acts of God (Bilu, 1987, 2000). To deal with these conditions, there is a need to appease God or the possessing agents or to confront them with invocations of God's powers by calling on him and invoking his holy names (Somer \& Saadon, 2000). The rituals are normally conducted by representatives of male-dominated religion and society, such as shamans, mystics, rabbis, imams, or Muslim clergy and psychics (Grisaru, Budowski, \& Witztum, 1997). Some rituals documented in Israel among Jews from North African descent have been influenced by black African traditions and often involve rhythmic movements and dance accompanied by drum beats (Somer \& Saadon, 2000). The desired result is typically a hypnotic trance, which reaches a peak with convulsive movements and loss of memory. Sometimes afflicted women disrobe during the ritual and verbalize profanities that are said to be the demon's words.

Jewish wisdom and dissociation. Jewish thought in the Land of Israel had regarded the self as being made up of subsystems long before Pierre Janet (1859-1947) introduced his dissociation theory and his model of the functional and structural elements of the mind (Janet, 1889). Possession trance in Judaism is probably best understood within the context of Kabbalist polypsychic philosophy. The Kabbalist book The Zohar (Book of Radiance, Tishbi, 1982) is a mainstay of Jewish sacred thought and describes the human psyche as being composed of three main souls: $n e f e s h$, which is a spiritual force that brings the dimension of vitality into being; ruach, which is responsible for human emotions and characteristics; and neshama, which is a spiritual-intellectual guiding soul whose task is to guide and correct evil traits. Many folkloristic 
possession tales inspired by Kabbalist tradition contain the term $d y b b u k$ (in Hebrew the term denotes a clinging, clutching, an adhering agent).

Recently, Somer (2004) analyzed sixteenth-century dybbuk accounts from the Near East and demonstrated a striking resemblance between these eyewitness accounts and modern attributes of Dissociative Identity Disorder (DID). Demonic beliefs were strongly held by many Jews who immigrated to modern-day Israel from Arab countries. In Morocco, for example, a former homeland of many Israeli Jews, demons were accorded a central role in structuring and explaining daily events (Crapanzano, 1973). Jews of the Maghreb integrated many demonic traditions of their neighboring Muslims into their spiritual rituals (BenAmi, 1969; Bilu, 1980, 1982). In fact, more than half of the 104 ailments identified among patients of Moroccan Jewish traditional healers in Israel turned out to be of demonic causation (Bilu, 1983, 1985). The synthesis of North (Bilu, 1987) and East African influences (Witztum, Grisaru, \& Budowski, 1996), Arab influences (Al-Krinawi, 2000; Daie, Witztum, Mark, \& Rabinowitz, 1992; Dwairy, 1993), and polypsychic Jewish mystical philosophy (Somer, 2004a; Witztum, Buchbinder, \& Van der Hart, 1990) have played an important role in the development of culture-sensitive assessment and treatment techniques not only for (what would be regarded by Western medicine as) hysterical (e.g., Somer, 1993; Van der Hart, Witztum, \& Friedman, 1992) and dissociative psychopathology (e.g., Somer, 1997a), but also for psychotic symptomatology (e.g., Greenberg, Witztum, \& Buchbinder, 1992) among traditional societies in Israel.

Dissociation and the trauma of the Holocaust. A 1993 examination of approximately 5,000 long-term psychiatric inpatients in Israel identified about 900 Holocaust survivors. Laub (2003) hypothesized that many of these patients could have avoided lengthy, if not lifelong, psychiatric hospitalizations had they been enabled by their therapists (and by society at large) to more openly share their severe persecution history. Instead, their traumatic experiences remained encapsulated, causing the survivors to lead a double life: a robot-like semblance to normality with incessant haunting by nightmares and flashbacks. Dissociation was a central finding in a study on elderly survivors of the Holocaust (Yehuda et al., 1996). The silence of the survivors never meant that the horror of their suffering was absent from behaviors, attachments, and parenting (Durst, 2003; Moskovitz, \& Krell, 1990). In fact, their inability to verbalize and openly process their pain and that which they inflicted on the second generation rendered some of their children more fragile and vulnerable. One of the more provocative Israeli studies on survivors of the Holocaust and their offspring by Solomon, 
Kotler, and Miculincer (1988) found that children of Holocaust survivors were more likely than other soldiers to develop PTSD following deployment in the Lebanon War. Barocas and Barocas (1983) reported not only on the alarming number of children of survivors seeking and requiring help, but also of the nature of their symptoms. They found that the offspring of Holocaust survivors presented symptomatology and psychiatric features bearing a striking resemblance to the concentration camp survivor syndrome described in the international literature, and that these children showed symptoms that would be expected if they had actually lived through the Holocaust. Yehuda et al. (1998) actually found correlations between the individual PTSD symptoms in the holocaust survivor parents and their children. Positive correlations were present for flashbacks, avoidance of situations that are reminders of the Holocaust, and emotional detachment. Additionally, there was a significant association between dissociative experiences, as reflected by DES scores in parents and children.

Dissociative amnesia among Israeli survivors of the Nazi persecution was also documented in several clinical case studies (e.g., Modai, 1994; Somer, 1994a) and other articles suggesting specific assessment procedures (Van der Hart \& Brom, 2000) as well as intervention techniques for the treatment of dissociative survivors of the Nazi genocide (e.g., Somer, 1995). Compelling testimonies from the survivors of the experiments on twins performed in Auschwitz by Dr. Mengele contained descriptions of traumatic dissociation such as:

A few of the twins insisted that they had no memories of Auschwitz whatsoever. Instead, they dwelt on the sadness of their postwar adult lives-their emotional upheavals, physical breakdowns, and longings for the dead parents they had hardly known. (Lagnado \& Dekel, 1991, p. 8)

The coping of Holocaust survivors with traumatic memories is of obvious interest to Israeli clinicians, as reflected in several studies (e.g., Mazor, Ganpel, Enright, \& Ornstein, 1990). Attempts have also been made to conceptualize the extraordinary compartmentalization of the horrors endured by persecuted Jewish children in terms of structural dissociation (Tauber, 1966). Among the most interesting inquiries performed in Israel on survivors of the Holocaust are the studies of Kaminer and Lavie on memory of dreams and mental health of survivors (e.g., Kaminer \& Lavie, 1991, 1993, 1996; Lavie \& Kaminer, 1991). They found that well-adjusted Holocaust survivors managed to banish memories of their 
wartime tribulations even from their dreams. Sleepers awakened from dreaming sleep in the sleep laboratory normally recall dreams about 80 percent of the time. The well-adjusted survivors, however, did so only about a third of the time. Survivors who had problems with work, family life, or health slept more fitfully and often dreamed that they were in danger or even back in the concentration camp. Dreams of the less-adjusted had significantly higher scores for general anxiety, guilt anxiety, diffused anxiety, general aggression, inwardly directed aggression, and interpersonal conflicts than the controls. The less-adjusted also dreamed significantly more than the other two groups about their childhood.

Despite the evidence that some survivors of the Holocaust repressed their memories of childhood trauma and continuously repressed fresh memories of relevant dream content, the doubts raised in North America about the very existence of repression of trauma and the veracity of repressed memories was faintly echoed in Israel as well.

Echoes of the "memory wars" in Israel. Israel does not tend to be a litigious society, and malpractice compensations awarded by Israeli courts have generally been quite modest. This may explain why, to the best of my knowledge, no damages have ever been awarded to plaintiffs in repressed/recovered memory malpractice suits in Israel. In fact, I am not aware of any such cases ever submitted to local courts. Nevertheless, the recovered memory controversy that has troubled the field in North America (Campbell, 2002) has not completely evaded Israel. In 1997, a conference entitled Childhood Trauma: Recovered Memory Therapy or False Memory Syndrome? was organized in Bar Ilan University near Tel Aviv. The keynote speaker was Dr. Elizabeth Loftus. Yielding to the demands of various advocacy groups for equal time in this highly contested issue, the university invited Dr. Richard Kluft to address the audience following Loftus' talk. The organizer of the conference, who also gave the opening address (Nachshon, 1977), presented his viewpoint in one more conference held in Israel during the following year (Nachshon, 1998a). He then proceeded to publish his thoughts locally (Nachshon, 1998b) and internationally (Nachshon, 2000).

It seems that at least one experimental research thesis on false memory utilizing a word recall paradigm was submitted to Bar Ilan University (Goldberg-Busheri, 2002), but this line of inquiry seems to have been largely abandoned. Other than an update on the "false memory syndrome," which was published during the same year by the journal of the Israel Medical Association (Nemetz, 2002), no further Israeli research projects on this issue have been identified. Yet, two influential 
Israeli newspapers featured science stories positing that false trauma memories can be installed in the minds of people (Siegel-Itzkovich, 1996; Slonim, 1997). An opposing view explaining the phenomenon of repressed, suppressed, recovered, and delayed reporting of child abuse memories was extensively presented locally and featured in Israel's leading psychotherapy journal (Somer, 1994b; Margalit \& Witztum, 1997a, 1997b), as well as published internationally (Somer \& Szwarcberg, 2001; Somer \& Weiner, 1996), and in a Hebrew article posted on the Internet (Somer, 1997b).

One of the most compelling sources on the validity of repressed memories of trauma has been the field of combat trauma. Israel, a country that has been battling for its existence since its independence in 1948, has borne the consequences of war trauma, making it possible to document combat-induced dissociative amnesia (e.g., Witztum, Margalit, \& Van der Hart, 2002), and the reality of forgetting traumatic experiences.

Advances in Israeli training, writing and publicity on dissociative disorders. Although Israeli psychoanalyst Emmanuel Berman wrote some of the first clinical articles on multiple personality disorder (MPD, now termed dissociative identity disorder, DID) ever published in the international clinical literature (Berman, 1973, 1974, 1975, 1981a, 1981b), it was only in 1987 that interest in this phenomenon budded in Israel. Van der Hart gave a two-day workshop on diagnosis and treatment of MPD for members of the Israel Hypnosis Society, and at the Third National Conference of the same society, I presented the first Hebrew language scholarly lecture on the diagnosis and treatment of MPD (Somer, 1987). Two years later, I also published the first Hebrew language peer-reviewed article on MPD (Somer, 1989), which was also commented on by Berman (1989). Since then, numerous in-service workshops and presentations on the topic have been held at the Haifa office of Maytal-Israel Institute for Treatment and Study of Stress.

The 12th International Congress of Hypnosis, held in Jerusalem in July of 1992, gave interested Israeli clinicians an opportunity to attend an MPD clinical workshop given by Dr. Richard P. Kluft (Van der Hart, 1993). Following this workshop, several clinicians expressed an interest in continued education in the field. This curiosity was probably reinforced by the popular non-fiction book on the subconscious mind that was published during the same period by a respected Bar Ilan University psychologist. The book featured a clear account on the differences between repression and dissociation (Orbach, 1992). 
On March 22, 1993, I presented the first Hebrew language workshop on the diagnosis and treatment of MPD. I taught the second workshop on this subject in the summer of the same year during the Israel Psychological Society's Annual Workshops. In the late 1990s, learning opportunities in Israel on dissociative disorders expanded to include graduate courses at the University of Haifa and at Bar Ilan University, as well as the official training course for the treatment of dissociative disorders offered in Israel through the International Society for the Study of Dissociation.

Several popular books on MPD sold in Israel during the 1980s and 1990s added to the public's interest in pathological dissociation. Among them were the Hebrew translations of Keyes' The minds of Billy Milligan (1995), published in Israel in 1982; Schreiber's Sybil (1973), Hebrew version published in 1987; and Fraser's My father's house: A memoir of incest and healing (1989), published in Hebrew in 1994. More recently in 2002, Cameron West's First person plural: My life as a multiple (1999) was also translated. Another very significant book to survivors, clinicians and scholars of chronic trauma was Herman's classic Trauma and recovery (1992), published in Hebrew in 1997.

Since the mid-1990s, when an Israeli organization of incest survivors was formed in Tel Aviv, a newsletter entitled Makhbarote Khesbone (Account Notebooks), containing mostly survivor poetry and art, has been published on a regular basis. Many of the contributions have described the inner world of structural dissociation and various other dissociative experiences. The turn of the millennium was marked by the publication of several compelling and commercial best-selling Hebrew language autobiographical accounts of Israeli survivors in which they described their dissociative experiences and psychopathology (e.g., Read, 2002; Shalev, 2000), recounted their treatment (Bergamn \& Sara, 1998) or shared their poetry (Shaz, 1999). Evidence of the growing professional interest and legitimization of post-abusive dissociative pathology is perhaps best demonstrated by the favorable book reviews on Read's (2002) autobiography published in Sihot-Israel Journal of Psychotherapy (Yahav, 2003) and in Psychoactualia, the newsletter of the Israel Psychological Association (Bar Sadeh, 2004). The latter contained illuminating paragraphs on dissociation. Another influential best-seller in Israel that credibly presented dissociative psychopathology was an "Irving Yalom-style" book that described in two separate chapters interesting vignettes on posttraumatic amnesia and dissociative psychopathology (Yovel, 2001). Finally, in 2004, a comprehensive Hebrew textbook on incest published as a joint venture between a commercial publisher and The Tel Aviv University featured several 
original chapters on the role of dissociation in the lives of survivors (e.g., Somer, E., 2004b; Somer, L. 2004; Scwarzberg \& Somer, 2004).

The Internet, rightfully dubbed "the information super-highway," has also developed into a useful source of Hebrew language information on dissociation. Pamphlets and articles on dissociative psychopathology are available for retrieval from Web sites for survivor support and advocacy (e.g., macom.org.il; voices.co.il; www.sahar.org.il); pharmaceutical companies (e.g., tevalife.co.il); and treatment centers (e.g., maytal.co.il; machoneitan.org.il). This surge in non- and semi-academic writing on severe dissociative disorders has also been accompanied by a plethora of professional writings on the subject published both locally, in $\mathrm{He}-$ brew (e.g., Somer, 1989, 1994b, 1995d), and internationally (e.g., Somer \& Nave, 2001; Somer, \& Yishai, 1997).

Dissociation: acceptance and advocacy. Further evidence of the budding awareness and interest in dissociative psychopathology in Israel was provided in a survey of the attitudes of 211 practicing clinicians in Israel toward dissociative disorders (DD) and DID (Somer, 2000a). Of the sample, $95.5 \%$ percent scored at or above the midpoint on a 5-point Likert scale measuring belief in the validity of DDs; $84.5 \%$ declared at least a moderate belief in the validity of DID. The average Israeli clinician surveyed had made 4.8 career-long DD diagnoses and carried an average of $1.05 \mathrm{DD}$ patients in his/her current caseload. The findings of this survey suggested that attitudes of Israeli clinicians were similar to those of North American clinicians, despite the geographical and cultural differences between them.

This growing awareness of the dissociative consequences of severe childhood traumatization was also utilized in a successful lobbying for the extension of the statute of limitations on incest crimes in Israel. In an attempt to interpret to the legislators some of the freeze responses of non-resisting (peri-dissociating) rape victims and in a separate effort to prolong the old 10-year statute of limitations, op-ed articles were published in a leading Israeli newspaper (e.g., Somer, 1993, December 9; Somer, 1994, May 24). Data on peri-traumatic dissociation (Somer, 1994c) and on delayed calls for help from incest survivors to the rape crisis hotlines were presented to members of the parliament's judicial committee (Nimrod \& Somer, 1995; Somer, 1994d). Incest victims' apparent aloofness and lack of resistance to alleged defendants' crimes have been difficult for the prosecution to explain to the Israeli courts. A number of workshops conducted by this author for state prosecutors of sex offenders in the mid-1990s aided attorneys to better understand delayed reporting and dissociative behavior that may have wrongly im- 
plied compliance. This growing understanding resulted in numerous invited affidavits and expert testimonies that were cited in the verdicts of numerous convicted offenders (e.g., Somer, 1994e).

Advances in Israeli dissociation research. Several instruments measuring dissociation have been translated into Hebrew over the years. Among them are the Dissociative Experiences Scale (H-DES; Somer, 1992); the Adolescent Dissociative Experiences Scale (H-A-DES; Somer, 1996); the Childhood Dissociation Questionnaire (1995b); the Structured Clinical Interview for Dissociative Disoders (H-SCID-D; 1995c); and the Multimodal Inventory of Dissociation (H-MID, 2002a). Research has shown that translated dissociation measures demonstrate strong internal consistencies, statistical reliabilities and construct validities when tested in the culturally diverse Israeli society (Somer \& Dell, 2005; Somer, Dolgin, \& Saadon, 2001). The most well-known assessment tool in the field, the DES, has been used in several graduate research theses supervised by Bar Ilan University (e.g., Herman, 1994; Krigel-Luski, 2001) and University of Haifa faculty (e.g., Avni, 2000; Bar, 1999; Finkelstein, 2004; Tzarfati, 2001).

The understandable interest of Israeli scholars in the course of PTSD development has steered some local research into the investigation of peri-traumatic antecedents of PTSD. A number of quantitative studies have examined the role of peri-traumatic dissociation in the development of PTSD (e.g., Shalev, Freedman, Peri, Brandes, \& Sahar, 1997; Shalev, Peri, \& Canetti, 1996) and identified it as significantly predictive of PTSD symptomatology four months following exposure to the traumatic event (Freedman, Brandes, Peri, \& Shalev, 1999). Several Israeli qualitative studies have shown that peri-traumatic dissociation plays an important role in the sexual victimization of female clients by their male psychotherapists (e.g., Ben Ari \& Somer, 2004; Somer \& Nachmani, in press; Somer \& Saadon, 1999) and in the coping of emergency room social workers vicariously traumatized during terror attacks (Peled-Avram, Ben-Yizhack, Gagin, Somer, \& Buchbinder, 2004; Somer, Buchbinder, Peled-Avram, \& Ben-Yizhack, 2004).

The role of dissociation in the etiology of suicide has been the focus of investigation for a Bar Ilan University research group led by Israel Orbach. These academics have shown that the life narrative of a suicidal person can be formulated in terms of a sequence of losses associated with unbearable mental pain, including the belief that a person is unneeded and useless (Orbach, 1994). The loathed self is said to be reified in actual self-hate, and a total mental offence on the self ensues. In a phe- 
nomenological investigation into mental pain, Orbach and Mikulincer (2000) concluded that the mental pain syndrome constitutes dissociative aspects that are predictable of suicidality, such as a sense of loss of control, emotional freezing, and estrangement (Orbach, 1994, 1996; Orbach, Kedem, Herman, \& Apter, 1995). They have also demonstrated that suicidal individuals experience their body differently from other populations and that these changes are related to suicidal behavior. Their bodily experiences include rejection of the body, detachment, numbness, physical anhedonia, and lack of self-care (e.g., Orbach, Lotem-Peleg, \& Kedem, 1995; Orbach, Mikulincer, King, Cohen, \& Stein, 1997).

Although this group seemed to be rather unconcerned by the etiology of these dissociative traits, several other Israeli publications attempted to show the link between childhood trauma and dissociative pathology, among them a book review (e.g., Somer, 1997c), literature review articles (e.g., Bar-Guy \& Shalev, 2001), and empirical research papers demonstrating significant statistical pathways connecting dissociation with childhood trauma, as well as with distressful introspectiveness and maladaptive daydreaming (Somer, 2002a, 2002b). The interest in the traumatic etiology of dissociative psychopathology was also reflected in several other Israeli research studies showing that posttraumatic dissociation was a predictor of a later proclivity to seek chemical dissociation through opiate use (Avni, 2000, 2002; Somer, 2003, in press; Somer \& Avni, 2003) and a probable factor in the tendency of survivors to seek solace in the arms of misguided male therapist offenders (Somer, 1999). The relationship between chronic traumatization and dissociative pathology was extensively described in several Hebrew language literature reviews published in the Journal of the Israel Medical Association (Eldar, Stein, Toren, \& Witztum, 1997), in the Israel Journal of Psychotherapy (Bar-Guy \& Shalev, 2001), and in a textbook on the psychological sequels of incest (Somer, 2004b).

Clinical articles. Although several Israeli scholars have contributed significantly to the promotion of the understanding of dissociation among professionals locally and worldwide, an examination of the list of contributors in the reference list of this essay reveals that much of the Israeli writing in the field can be attributed to a small number, most of whom are academics rather than field workers. My examination of the programs offered by local psychiatry, social work and psychology conferences has revealed that the field of dissociation is under-represented in these meetings. The picture is not much different where clinical pub- 
lications on dissociative psychopathology are concerned. A few Israeli clinicians have contributed to the understanding of such clinical issues as the relationship between hypnosis and structural dissociative phenomena (Arlow, 1992), the relationship between hypnotic trance and dissociation (Somer, 1995d), and the manifestations of dissociation in the artwork of dissociative clients (Somer \& Somer, 1997a, 1997b). Clinical articles by Israeli therapists have suggested various treatment strategies, including short-term therapies in posttraumatic conversion reactions (Daie \& Witztum, 1991; Grisaru, Gelbar, \& Witztum, 1999) and techniques for working with aging survivors (Somer, 2000b), but good case studies and treatment-oriented articles in Hebrew are scarce, possibly reflecting the early evolutionary state of the field in Israel.

\section{CONCLUSION}

This essay describes the field of dissociation study in Israel. Well over 100 cited publications addressing a broad array of topics were presented. This literature review seems to indicate that dissociation is a useful paradigm that has aided Israeli scholars in the understanding of disavowed experiences in a variety of contexts. Israeli anthropologists, scholars of religion, personality researchers, clinical social workers, psychoanalysts, clinical psychologists, psychiatrists, substance abuse counselors, sleep disorder specialists, and social activists have shared their observations on the role that dissociation has played in the lives of oppressed and traumatized Israelis. The findings are encouraging. The growing awareness regarding the role of dissociation in the mental health of traumatized Israelis guarantees that earlier attention will be given to unprocessed trauma, thereby offering enhanced chances of recovery. The evidence provided here regarding the usefulness of the dissociative model in an ethnically diverse Middle Eastern country such as Israel also renders further support to the validity of dissociation theory, habitually contested by some North American clinicians and memory scholars. Despite the relative wealth of knowledge on dissociation disseminated by Israeli writers, a good deal has been accomplished by relatively few. Future efforts should be invested in promoting the teaching of dissociative dynamics to Israeli clinicians, with the aim of augmenting diagnostic and treatment skills to offset a pathology mostly associated with oppression and abuse. 


\section{REFERENCES}

Arlow, J.A. (1992). Altered ego states. Israel Journal of Psychiatry and Related Sciences, 29(2), 65-76.

Avni, R. (2000). The phenomenology of drug abuse among high-dissociating recovering heroin addicts. Thesis submitted to the University of Haifa.

Avni, R. (2002). Khavayat ha'nitook hamooseget be'emtzoot hasheemoosh be'sumeem [The experience of dissociation achieved through substance use]. Miksumim-Newsletter of Ministry of Welfare Service for the Treatment Drug Users, 1, 54-57

Al-Krenawi, A. (2000). Etno-psykhiatria ba'khevra ha'bedouit-araveet ba'negev [Ethno-psychiatry among the Bedouin-Arab of the Negev]. Tel-Aviv: Hakibbutz Hameuchad Publishing House.

Al-Krenawi, A., Maoz, B., Shiber, A. (1995). Sheloov ma'arkhote modernioterefooiote im amahmiote-datiote be'tipool nafshee be'bedouiim [The integration of modern-medical systems with folkloristic-religious systems in the psychological treatment of the Bedouin], Sihot-Israel Journal of Psychotherapy, 10(1), 42-48.

Bar, E. (1999). The relationship between self-awareness, dissociation, emotional distress and well-being, and traumatization in women. Thesis submitted to the University of Haifa.

Bar-Guy, N., \& Shalev, A. (2001). Hashpaote shel hit'aleloot beshnote hayaldoot al psikhopathologhia bemvoogarim [The effects of child abuse on adult psychopathology]. Sihot-Israel Journal of Psychotherapy, 6(3), 180-194.

Bar Sadeh, N. (2004). Maya Read-"Shvooya." Psychoaktualia, (July, 2004 issue), 18-21.

Barocas, H., \& Barocas, C. (1983). Wounds of the fathers: The next generation of Holocaust victims. International Review of Psychoanalysis, 5, 331-341.

Ben-Ami, I. (1969). Nukhekhoot shedim ba'bah'it ha'yahoodie maroccai [The presence of the demons in the Jewish Moroccan house] Proceedings of the Fifth World Congress for Judaic Studies. Jerusalem: The World Organization for Judaic Studies.

Ben Ari, A., \& Somer, E. (2004). The aftermath of therapist-client sex: Exploited women struggle with the consequences. Clinical Psychology and Psychotherapy, $11,126-136$.

Bergamn, Z., \& Sara (1998). Ahavah zeh loh sukeen [Love is not a knife]. Tel Aviv: Yediot Aharonot.

Berman, E. (1973). The development and dynamics of multiple personality. Ann Arbor, Michigan: University Microfilms International.

Berman, E. (1974). Multiple personality: Theoretical approaches. Journal of the Bronx State Hospital, 2, 99-107.

Berman, E. (1975, August). Tested and documented split personality: Veronica and Nelly. Psychology Today, pp. 78-81.

Berman, E. (1981a). Multiple personality: Psychoanalytic perspectives. International Journal of Psychoanalysis, 62, 283-300. 
Berman, E. (1981b). "Pram lamentis," or she's a young thing and cannot leave her mother. Family Process, 20, 449-451.

Berman, E. (1989). Comments on Eli Somer's article on Multiple Personality. SihotIsrael Journal of Psychotherapy, 3(3), 225.

Bilu, Y. \& Beit Hallahmi, B. (1989). Dybbuk possession as a hysterical symptom. Psychodynamic and socio-cultural factors. Israel Journal of Psychiatry, 26(3), 138-149.

Bilu, Y. (1980). The Moroccan demon in Israel. The case of 'Evil Spirit Disease.' Ethos, 8, 1, 24-38.

Bilu, Y. (1982). Tafkeed hashydeem be'hasbare makhalote bekarave yehooday morocco be' Israel [The role of demons in explicating illnesses among Moroccan Jews in Israel]. Jerusalem Studies in Jewish Folklore, 2, 102-123.

Bilu, Y. (1983). Ha'dybbuk ba'yahadoot. Makhalut nefesh ke'mashuv tarbooti [The Dybbuk in Judaism. Mental disorder as a cultural resource]. Jerusalem Studies in Jewish Thought, 2, 4, 529-563.

Bilu, Y. (1985). The taming of the deviants and beyond. An analysis of Dybbuk Possession and exorcism in Judaism. In: Boyer, L.B., Grolnick, S.A. (Hg.): The Psychoanalytic Study of Society, 11. New Jersey (The Analytic Press), 1-32.

Bilu, Y. (1987). Dybbuk possession and mechanisms of internalization and externalization. In: Sandler, J. (Hg.): Projection, Identification, and Projective Identification. New York (International Universities Press), 163-178.

Bilu, Y. (2000). Islai, Dybbuk, Zar: Neevdalote tarbootiote ve'hamshikhiyoot historeet be'makhalote ikhooz [Islai, Dybbuk, Zar: Cultural differentiation and historical continuity in possession afflictions in Jewish communities]. Pe'amim-Studies in Oriental Jewry, 85, 131-148.

Campbell, P.C. (2002). Hypnosis, demand characteristics, and "Recovered Memory" Therapy. Prevention \& Treatment, 5, Article 40, posted October 18, http://www.journals. apa.org/prevention/volume5/pre0050040c.html accessed Oct. 4th, 2004.

Crapanzano, V. (1973). The Hamadsha: A study in Moroccan ethno-psychiatry. Berkeley: University of California Press.

Daie, N., \& Witztum, E. (1991). Short-term strategic treatment in traumatic conversion reactions. American Journal of Psychotherapy, 55, 335-347.

Daie, N., Witztum, E., Mark, M., \& Rabinowitz, S. (1992). The belief in the transmigration of souls: Psychotherapy of a Druze patient with severe anxiety reaction. British Journal of Medical Psychology, 65, 119-130.

Durst, N. (2003). Child-Survivors of the Holocaust: Age-specific traumatization and the consequences for therapy. American Journal of Psychotherapy, 57, (4) 499-518.

Dwairy, M., \& Van Sickle, T.D. (1996). Western psychotherapy in traditional Arabic societies. Clinical Psychology Review, 16 (3), 231-299.

Dwairy, M. (1993). Mental health among Arabs in Israel (Hebrew). Paper presented at mental health conference, Nazareth, Israel.

Eldar, Z., Stein, D., Toren, P., \& Witztum, E. (1997). Tismonayt hafra'at zehut dissotziyativit be'yeladeem u'mitbagreem [Dissociative Identity Disorder in children and adolescents]. Harefuah-Journal of the Israel Medical Association, 133(1-2), $36-40$. 
Fraser, S. (1989). My father's house: A memoir of incest and healing. London: Virago. The book was published (1994) in Israel in Hebrew by Am Oved.

Finkelstein, M. (2004). Traumatic stress, coping resources and psychological adjustment among Ethiopian immigrants in Israel. Doctoral thesis submitted to the University of Haifa.

Freedman, S.A., Brandes, D., Peri, T., \& Shalev, A. (1999). Predictors of chronic post-traumatic stress disorder: A prospective study. British Journal of Psychiatry, $174,353-359$.

Goldberg-Busheri, M. (2002). Real and false memories: Discrimination according to accessibility. Graduate Theses submitted to Bar Ilan University.

Greenberg, D., Witztum, E., \& Buchbinder, J., (1992). Mysticism and psychosis: The fate of Ben Zoma. British Journal of Medical Psychology, 65, 223-235.

Grisaru N, Budowski D, \& Witztum E. (1997). Possession by the 'Zar' among Ethiopian immigrants to Israel: Psychopathology or culture-bound syndrome? Psychopathology, 30(4), 223-33.

Grisaru, N., Gelbar, D., \& Witztum, E. (1999). Tipool astrateggi meshoolove be'narcoanalysa, be'hafra' a conversiveet posttraumatit [An integrative strategic treatment with narcoanalysis in a posttraumatic conversive disorder]. Sihot-Israel Journal of Psychotherapy, 13(2), 135-141.

Herman, L. (1994). Changes in attitudes toward life and death and in dissociation. Thesis submitted to Bar Ilan University.

Herman, L. J. (1992). Trauma and recovery. NY: Basic Books. The book was published (1997) in Israel in Hebrew by Am Oved.

Janet, P. (1889). L’Automatisme psychologique. Paris: Félix Alcan. New edition: Société Pierre Janet, Paris, 1973.

Kaminer, H., \& Lavie, P. (1991). Sleep and dreaming in Holocaust survivors. The Journal of Nervous and Mental Disease, 179 (11), 664-669.

Kaminer, H., \& Lavie, P. (1993). Sleep and dreams in well-adjusted and less adjusted Holocaust surviviors. In M. S. Stroebe, W. Stroebe, \& R. O. Hansson (Eds.), Handbook of bereavement: Theory, research, and intervention (pp. 331-345). Cambridge, MA: Cambridge University Press.

Keyes, D. (1995). The minds of Billy Milligan. New York: Bantam, The book was published (1982) in Israel in Hebrew by Cherikover.

Krigel-Luski, Y. (2001). Reference to the body and investment in it, dissociation and defense mechanisms among adolescent girls diagnosed with Anorexia Nervosa and suicidal girls. Thesis submitted to Bar Ilan University.

Lagnado, L.M., \& Dekel, S.C. (1991). Children of the flames: Dr. Josef Mengele and the untold story of the twins of Auschwitz. New York: William and Morrow.

Laub, D. (2003). Video testimony pilot study of psychiatrically hospitalized Holocaust survivors, Holocaust Trauma Project, Yale University Genoside Studies Program, http://www.yale.edu/gsp/trauma_project/index.html accessed Oct.1, 2004.

Lavie, P., \& Kaminer, H. (1996). Sleep, dreaming, and coping style in Holocaust survivors. In D. Barrett (Ed.), Trauma and dreams (pp. 114-124). Cambridge, MA: Harvard University Press.

Lavie, P., \& Kaminer, H. (1991). Dreams that poison sleep: Dreaming in Holocaust survivors. Dreaming: Journal of the Association for the Study of Dreams, 1(1), 11-21. 
Margalit, H., \& Witztum, E. (1997a). Trauma, amnesia, ve'dissotziatzia: Heybeteam kliniyim ve'teyoretyim, khaylek beit-Skeerah tayoretit [Trauma, amnesia and dissociation-Clinical and theoretical aspects. Part I: Theoretical revue]. SihotIsrael Journal of Psychotherapy, 11 (3), 214-217.

Margalit, C. \& Witztum, E. (1997b). Trauma, amnesia, ve'dissotziatzia: Heybeteam kliniyim ve'teyoretyim, khaylek beit-Tey'oor mikray [Trauma, amnesia and dissociation: Clinical and theoretical perspectives. Part two-A case study]. Sihot-Israel Journal of Psychotherapy, 12(1), 44-50.

Maslow, A. (1970). Motivation and personality (2nd ed.). New York: Harper \& Row.

Mazor, A., Ganpel, Y., Enright, R.D., \& Ornstein, R. (1990). Holocaust survivors: Coping with posttraumatic memories in childhood and 40 years later. Journal of Traumatic Stress, 3, 11-14.

Modai, I. (1994). Forgetting childhood: A defense mechanism against psychosis in a Holocaust survivor. In T. L. Brink, (Ed.), Holocaust survivors' mental health. New York: The Haworth Press, Inc.

Moskovitz, S., \& Krell, R. (1990). Child survivors of the Holocaust: Psychological adaptations to survival. Israel Journal of Psychiatry and Related Services, 27, 81-91.

Nachson, I. (1997). Me'zeekarone mashookhzar le'zeekarone mesooluf ve'khuzarah [From recovered memory to false memory, and back]. Opening address delivered at the meetings of a conference on Childhood Trauma: Recovered Memory Therapy or False Memory Syndrome? Ramat-Gan, June, 1997.

Nachson, I. (1998a). Me'zeekarone mashookhzar le'zeekarone mesooluf ve'khuzarah [From recovered memory to false memory and back]. Invited address delivered at a conference on Therapist-Client Relationships: Ethical and Legal Aspects. Tel-Aviv, September, 1998.

Nachson, I. (1998b). Me'zeekarone mashookhzar le'zeekarone mesooluf ve'khuzarah [From recovered memory to false memory, and back]. Psychologia, 7, 7-23.

Nachson, I. (2000). Truthfulness, deception and self-deception in recovering true and false memories. International Journal of Victimology, 8, 1-18.

Nemetz. B. (2002). Tismonayt ha'zikron ha'medoomay-Tmoonut matzav udkanit [The false memory syndrome-A current update]. Harefuah-Journal of the Israel Medical Association, 141(8), 726-730.

Nimrod, N., \& Somer, E. (1995). Be'Gove Ha'Arayot: Pneeyote telephoniyote le'merkazay ha'seeyooah shel nifgeote gilooy arayote [Incest survivors calls to the rape crisis centers' hotlines in Israel]. Tel Aviv: The Israel Association of Rape Crisis Centers. A statistical report commissioned by the chair of the Knesset's Judiciary Committee and presented to the committee members.

Orbach, I. (1992). Olamot Nistarim-Hitbonanoot be-T at Hahakara [Hidden worldsObservations of the sub-conscious]. Tel Aviv: Schoken.

Orbach, I. (1994). Dissociation, physical pain and suicide: A hypothesis. Suicide and Life-Threatening Behavior, 24(1), 68-79.

Orbach, I. (1996) The role of the body experience in self-destruction. Clin Child Psychol Psychiatry, 1, 607-619.

Orbach, I., Kedem, P., Herman, L., \& Apter, A. (1995). Dissociative tendencies in suicidal, depressed, and normal adolescents. Journal of Social and Clinical Psychology, 14(4), 393-408. 
Orbach, I., Lotem-Peleg, M., \& Kedem, (1995). Attitudes towards the body in suicidal and nonsuicidal adolescents. Suicide and Life-Threatening Behavior, 25, 211-221.

Orbach, I., \& Mikulincer, M. (2000). Mental pain: Conceptualization and operationalization. Presented at the annual conference of the American Association of Suicidology Los Angeles.

Orbach, I., Mikulincer, M., King, R., Cohen, D., \& Stein, D. (1997). Thresholds and tolerance of physical pain in suicidal and nonsuicidal adolescents. Journal of Consulting and Clinical Psychology, 65, 646-652.

Peled-Avram, M., Ben-Yizhack, Y., Gagin, R., Somer, E., \& Buchbinder, E. (2004). Tgoovote ve'tzrakheem regshee'im shel ovdeem sotzialee'im be'ayrooah rav-nifguyim [Emotional responses and needs of social workers in a mass disaster]. Hevra U'rvacha (Society and Welfare), 24 (2), 181-200.

Read, M. (2002). Shvooya: Kroneekah shel Gelooy arayot MIktzo'i-Seepoor autobiographi. [Captive: A chronicle of professional incest-An autobiographical account]. Tel Aviv: Tamuz.

Schreiber F.R. (1973). Sybil: The true story of a woman possesses by sixteen separate personalities. Chicago: Regnery, The book was published in Israel Hebrew in 1987 by Kineret.

Scwarzberg, S., \& Somer, E. (2004). Khaseefut hasode: Gormim meodedim ume'ukvim et gilooy sode hapgiah bekerev korbanote hit'alelute meneet bayaldoot [Breaking the Silence: facilitating and inhibiting factors in the disclosure of incest among survivors of child sexual abuse]. In Z. Seligman and Z. Solomon (Eds.), Hasode ve'shevroh: Soogiote be'gelooy arayote [Critical and Clinical Perspectives on Incest]. Tel Aviv: Hakibbutz Hameuchad and Tel Aviv University.

Shalev, R. (2000). Behten [Belly]. Tel Aviv: Carmel.

Shalev, A.Y., Freedman, S., Peri, T., Brandes, D., \& Sahar, T. (1997). Predicting PTSD in trauma survivors: Evaluation of self-report and clinician-administered instruments. British Journal of Psychiatry, 170, 558-564.

Shalev, A.Y., Peri, T., \& Canetti, L. (1996). Predictors of PTSD in injured trauma survivors: A prospective study. American Journal of Psychiatry, 153, 219-225.

Shaz (1999). Rikood Ha'mashooga'at [The dance of the madwoman]. Tel Aviv: Hakibutz Ha'meuchad.

Siegel-Itzkovich, J. (1996, May 19). You must remember this. Jersalem Post, p. 7.

Slonim, N. (1997, October, 15). Massa Mefookpuck el he'avar [A dubios journey into the past]. Ha'aretz daily, p.8.

Solomon, Z., Kotler, M., \& Mikulincer, M. (1988). Combat-related posttraumatic stress disorder among second-generation Holocaust survivors: Preliminary findings. American Journal of Psychiatry, 145, 865-868.

Somer, E. (1987, November). Ishiyoot meroobut puneem: Akronot Ivkhoon ve'teepool [Multiple personality: Diagnosis and treatment principles]. Paper presented at the Third National Conference of the Israel Hypnosis Society. Tel Aviv.

Somer, E. (1989). Ishiyute meroobat puneem: Hearote al Ivkhoon, tipool U'ragushote ha'metapale [Multiple personality: Comments on diagnosis, treatment and therapist's feelings]. Sihot-Israel Journal of Psychotherapy, 3(3), 101-106. 
Somer, E. (1992). Soolum Khavayot dissotzyativiot [Translation into Hebrew and adaptation of the Dissociative Experience Scale (H-DES)] (E.B. Carlson and F.W. Putnam).

Somer, E. (1993). Tismonet Ikhooz be'Ishiyoot histriyonit: Geroosh shedim ve'psikhoterapia [Possession syndrome in a hysterionic personality: Exorcism and psychotherapy]. Sihot-Israel Journal of Psychotherapy, 8, 40-47.

Somer, E. (1993, December 9). Ha'makka ha' 81 [The 81st blow, An Op-page article commenting on the Supreme Court's acquittal of a father convicted of incest]. Ha'aretz Daily Newspaper.

Somer, E. (1994a). Hypnotherapy and regulated uncovering in the treatment of older survivors of Nazi persecution. In T. L. Brink (Ed.), Holocaust survivors' mental health (pp. 47-65). New York: The Haworth Press, Inc.

Somer, E. (1994b). Hizakhroot meookheret behitaleloot bayaldoot: Zikhronot melakhooti'im o ha' etgar haba be'psikhoterapia? [Delayed recall of child abuse: False memories or the next challenge for psychotherapy?]. Sihot-Israel Journal of Psychotherapy, 9(1), 46-50.

Somer, E. (1994c). Tgoovote nufshiyote le'traumat ha'oness [Psychological reactions to rape trauma]. A document presented to members of the Knesset as part of testimony given to the Judicial Committee in session on change of legislation regarding sex offenses.

Somer, E. (1994d). Trauma be'gil ha'yaldoot: Ovdan Zikaron ve'khasifa mooshheyt. [Childhood trauma: Delayed recall and reporting]. A position paper commissioned by the National Council for the Protection of the Child for presentation to the Knesset's Judiciary Committee in session on changing the statute of limitations regarding child abuse. Also appears in T. Morag (Ed.), Repressed testimony or oppressed childhood: On the statute of limitations in cases of sex offences in the family. Jerusalem: National Council for the Child, Center for Research and Policy.

Somer, E. (1994e). Yekholet ha'hitnagdoot shel yalda hanimtzeyt be'gilooy arayot [The capacity of an incest victim to resist]. A position paper submitted to the National Council for the Child as part of assistance given to the State Attorney's Office of Criminal Appeal 851/93.

Somer, E. (1994, May 24). Assiyat deen gum begilooy arayote [No statute of limitation for child abuse, An Op-page article advocating a change in the statute of limitation regarding sexual child abuse crimes]. Ha'aretz Daily Newspaper, p. 8.

Somer, E. (1995a). Hynotherapy in the treatment of older Holocaust survivors: Overcoming dissociation. In E. Bolcs, M. Guttman, M. Martin, M. Mende, H. Kanitschar, \& H. Walter (Eds.), Hypnosis-connecting discipline: Proceedings of the 6th European Congress of Hypnosis in Psychotherapy and Psychosomatic Medicine (pp. 213-217). Parkersdorf/Vienna: Medizinisch-Pharmazeutische Verlagsgeselschaft.

Somer, E. (1995b). Shay'e'lone dissotzyatzya ba'yaldoot [Translation into Hebrew and adaptation of the Childhood Dissociation Questionnaire] (F. Putnam).

Somer, E. (1995c). Rayayon klini moovnay le'hafra'ote dissozyativiote [Translation into Hebrew and adaptation of the Structured Clinical Interview for Dissociative Disoders (SCID-D)] (M. Steinberg). 
Somer, E. (1995d). Trauma, trance ve'abreaktzia behafra'at zehoot dissotziativit [Trauma, trance and abreaction in dissociative identity disorder]. Hypnoza, 1(1), 8-15.

Somer, E. (1996). Soolum Khavayot dissotzyativiot-Mitbugreem [Translation into Hebrew and adaptation of the Adolescent-Dissociative Experience Scale (H-A-DES)] (J. Armstrong, F.W. Putnam and E. B.Carlson).

Somer, E. (1997a). Paranormal and dissociative experiences in middle eastern Jews in Israel: Diagnostic and treatment dilemmas. Dissociation, 10(3), 174-181.

Somer, E. (1997b). Zeekarone traumati: Massa Mefookpuck el he'avar oh massa mefah'raykh el avar mefookpuck? http://www.maytal.co.il/heb_articles/article_ 8.html accessed Oct. 6, 2004.

Somer, E. (1997c). Book review on: J. Silberg (Ed.), The Dissociative Child: Diagnosis, treatment and management. Sihot-Israel Journal of Psychotherapy, 11(3), 243-245.

Somer, E. (1999). Yekhaseem Makbeelim: Petooy ve'neetzool meenee be'psikhoterapia ve'yeootz [Dual Relationships: Seduction and sexual exploitation in counseling and psychotherapy]. Tel Aviv: Papyrus-Tel Aviv University Publishing House.

Somer, E. (2000a). Israeli mental health professionals' attitudes towards dissociative disorders, differential diagnosis considered, and reported incidence. Journal of Trauma and Dissociation, 1(1), 21-44.

Somer, E. (2000b). The effects of incest in aging survivors: Psychopathology and treatment issues. Journal of Clinical Geropsychology, 6(1), 53-61.

Somer, E. (2002a). Ha'metzay ha'rov maymady shel dissotzyatzya [Translation into Hebrew and adaptation of the Multi-modal Inventory of Dissociation (H-MID]) (Paul Dell).

Somer, E. (2002b). Posttraumatic dissociation as a mediator of the effects of trauma on distressful introspectiveness. Social Behavior and Personality, 30(7), 671-682.

Somer, E. (2002c). Maladaptive daydreaming: A qualitative inquiry. Journal of Contemporary Psychotherapy, 32(2), 195-210.

Somer, E. (2003a). Prediction of abstinence from heroin addiction by childhood trauma, dissociation, and extent of psychosocial treatment. Addiction Research and Theory, 11(5), 339-348.

Somer, E. (2004a) Trance possession disorder in Judaism: Sixteenth-century dybbuks in the Near-East. Journal of Trauma and Dissociation, 5(2), 131-146.

Somer, E. (2004b). Hitaleloot bayaldoot ve'hafraote disotzyativiot [Childhood trauma and dissociative disorders]. In Zeligman, z., \& Solomon, Z. (Eds.) (2004). Hasode ve'sheevroh: Gilooy arayot [Breaking the secret of incest]. Tel Aviv: SIfriyat Hapoalim.

Somer, E. (in press). Opiate use disorder and dissociation. In P.F. Dell, \& J. O'Neil (Eds.), Dissociation and the dissociative disorders: DSM-V and beyond.

Somer, E., \& Avni, R. (2003b). Dissociative phenomena among recovering heroin users and their relationship to duration of abstinence. Journal of Social Work Practice in the Addictions, 3(1), 25-38.

Somer, E., Buchbinder, E. Peled-Avram, M., \& Ben-Yizhack, Y. (2004). The stress and coping of Israeli emergency room social workers following terrorist attacks. Qualitative Health Research, 14(10), 1077-1093. 
Somer, E., \& Dell, P. F. (2005). The development and psychometric characteristics of the Hebrew version of the Multidimensional Inventory of Dissociation (H-MID): A valid and reliable measure of pathological dissociation. Journal of Trauma and Dissociation.

Somer, E., Dolgin, M., \& Saadon, M. (2001). Validation of the Hebrew version of the Dissociative Experiences Scale (H-DES) in Israel. Journal of Trauma and Dissociation, 2(2), 53-66.

Somer, E., \& Nave, O. (2001). An ethnographic study of former dissociative disorder patients. Imagination, Cognition, and Personality, 20(1), 315-346.

Somer, E., \& Nachmani, I. (2005). Constructions of therapist-patient sex: An analysis of retrospective reports by former Israeli patients. Sexual Abuse: A Journal of Research and Treatment.

Somer, E., \& Saadon, M. (1999). Therapist-client sex: Clients' retrospective reports. Professional Psychology: Research and Practice, 30(5), 504-509.

Somer, E., \& Saadon, M. (2000). Stambali: Dissociative possession and trance in a Tunisian healing dance. Transcultural Psychiatry, 37(4), 579-609.

Somer, L. (2004). Olama hapnimi shel nefga' at gelooy arayote: Iyoorim betzevah uvetzurah metokhe tahalikh shel tipool bemtzaoot yetzirah [The inner world of an incest victim: Illustrations in color and form from an art therapy process. In Z. Seligman and Z. Solomon (Eds.) Hasode ve'shevroh: Soogiote be'gelooy arayote [Critical and Clinical Perspectives on Incest]. Tel Aviv: Hakibbutz Hameuchad and Tel Aviv University.

Somer, L., \& Somer, E. (1997a). Phenomenological and psychoanalytic perspectives on a spontaneous artistic process during psychotherapy for dissociative identity disorder. The Arts in Psychotherapy, 24(5), 419-430.

Somer, L., \& Somer, E. (1997b). Heybetim psikhodinami'im shel avodote omanoot be'hafra' at zehoot disotziativit [Pychodynamic perspectives on art work in dissociative identity disorder]. Sihot-Israel Journal of Psychotherapy, 11(3), 183-194.

Somer, E., \& Szwarcberg, S. (2001). Variables in delayed disclosure of child sexual abuse. American Journal of Orthopsychiatry, 71(3), 332-341.

Somer, E., \& Yishai, R. (1997). Handwriting examination: Can it help in establishing authenticity in dissociative identity disorder? Dissociation, 10(2), 114-119.

Somer, E., \& Weiner, A. (1996). Dissociative symptomatology in adolescent diaries of incest victims. Dissociation, 9(3), 197-209.

Tauber, Y. (1996). The traumatized child and the adult: Compound personality in child-survivors of the Holocaust. Israel Journal of Psychiatry and Related Sciences, 33, 228-238.

Tishbi, Y. (1982). Torat ha-Zohar [The teachings of the Zohar]. Jerusalem: Mosad Bialik.

Tzarfati, A. (2001). Posttraumatic response among soldiers who were injured in military activity: The relation to peritraumatic dissociation and to history of prior trauma. Thesis submitted to the University of Haifa.

Van der Hart, O. (1993). Multiple Personality in Europe: Impressions. Dissociation, $5(2 / 3), 102-115$.

Van der Hart, O., \& Brom, D. (2000). When the victim forgets: Trauma-induced amnesia and its assessment in Holocaust survivors. In A. Shalev, R. Yehuda \& A.C. McFarlane (Eds.), International handbook of human response to trauma (pp. 233248). New York: Kluwer Academic/Plenum. 
Van der Hart, O., Witztum, E., \& Friedman, B. (1992). From hysterical psychosis to reactive dissociative psychosis. Journal of Traumatic Stress, 6, 43-64.

West, C. (1999). First Person Plural: My Life as a Multiple, NY: Hyperion. The book was published (2002) in Israel in Hebrew by Ma' ariv.

Witztum E., Grisaru, N., \& Budowski, D. (1996). The 'Zar' possession syndrome among Ethiopian immigrants to Israel: Cultural and clinical aspects. British Journal of Medical Psychology, (3), 207-25.

Witztum, E., Buchbinder, J.T., \& Van der Hart, O. (1990). Summoning a punishing angel: Treatment of a depressed patient with dissociative features. Bulletin of the Menninger Clinic, 54, 524-537.

Witztum, E., Margalit, C., \& Van der Hart, O. (2002). Combat-induced dissociative amnesia: Review and case example of generalized dissociative amnesia. Journal of Trauma and Dissociation, 3(2), 35-55.

Yahav, (2003). Book review on "Shvooya" by Maya Read. Sihot-Israel Journal of Psychotherapy, 17(3), 111-113.

Yehuda, R., Elkin, et al. (1996). Dissociation in aging Holocaust survivors. American Journal of Psychiatry, 153, 935-940.

Yehuda, R., Schmeidler, J., Elkin, A., Houshmand, E., Siever, L., Binder-Brynes, K., Wainberg, M., Aferiot, D., Lehman, A., Guo, L.S., \& Yang, R.K., (1998). Phenomenology and psychobiology of the intergenerational response to trauma. In Danieli, Y. (Ed) Intergenerational Handbook of Multigenerational Legacies of Trauma. http://www.trauma-pages.com/yehuda97.htm retrieved Oct. 1, 2004.

Yovel, Y. (2001). Se'arat nefesh [Mindstorm]. Tel Aviv: Keshet. 